\title{
The way to improve safety of pedestrian traffic at unregulated pedestrian crossing
}

\author{
Boris Kalmykov ${ }^{1, *}$, Olga Kalmykova ${ }^{1}$, and Mihail Kalmykov ${ }^{2}$ \\ ${ }^{1}$ Institute of the Service Sector and Entrepreneurship (branch) of the DSTU, 147, Shevchenko Street, \\ Shakhty 346500 Rostov region, Russia \\ ${ }^{2}$ Southern Federal University, 105/42 Bolshaya Sadovaya Str., 344006 Rostov-on-Don, Russia
}

\begin{abstract}
The article analyzes accident rate on the roads in Rostov region. Among total number of accidents, one of the "first" leading places is a collision with a pedestrian. Consequently, work in the field of improving road safety at unregulated pedestrian crossings is relevant. Analysis of research and patent search for devices that increase safety of a pedestrian when moving on a pedestrian crossing showed that there is the need to expand the range of such devices. As a result, the article presents a description of the new way to improve safety of pedestrian traffic at unregulated pedestrian crossing.
\end{abstract}

\section{Introduction}

The number of road traffic accidents (RTA) with injured pedestrians crossing the carriageway at pedestrian crossings is gradually decreasing. In 2020, there were 18,849 such accidents. However, the number of collisions with pedestrians moving along a pedestrian crossing, committed through the fault of drivers, on the contrary, continues to grow and in 2020 is 17381 . The largest number of accidents - 13634, occurred at unregulated pedestrian crossings.

The statistics presented on the official website of the State Traffic Safety Inspectorate of the Ministry of Internal Affairs for Russia: the number of injured pedestrians decreased by $3 \%$, and the number of collisions with pedestrians increased by $3.5 \%$ compared to 2018,2019 suggests that the level of external passive safety of motor vehicles funds (ATC) operated in Russia has increased significantly. And, consequently, the injured pedestrians received minor injuries [2-5].

The second conclusion that can be drawn after analyzing these statistics of road accidents is that despite the more advanced designs of vehicles, discipline of drivers who manage it continues to decline.

Another problem is the lack of lighting at unregulated pedestrian crossings. According to the same statistics, the majority of collisions with pedestrians occur at night. Therefore, the third conclusion can be made that it is necessary to light the crossing at night or warn drivers in advance about the presence of pedestrians on it [6-8].

\footnotetext{
* Corresponding author: job@sssu.ru
} 
Thus, it is necessary to consider the possibility of changing safety requirements for the passage of pedestrian crossings, as well as to modernize unregulated pedestrian crossings.

\section{Purpose of study}

This article proposes a new approach to the design of unregulated pedestrian crossings by equipping it with devices designed to force the vehicle to stop.

The object of the research is unregulated pedestrian crossings located on the road network in settlements.

The subject of the study is to improve road safety in areas of unregulated pedestrian crossings.

\section{Materials and methods}

Let's consider several ways to improve traffic safety at unregulated pedestrian crossings. 1) The way of notifying drivers about the presence of a pedestrian at a pedestrian crossing.

The invention is aimed at notifying the driver about the presence of a pedestrian who moves along the crossing with the help of an LED searchlight and a window that simulates the operation of a traffic light. In summary, the device of the invention consists of [9]: "of support 1 (Figure 1), on the inclined part 2 of which an LED floodlight 3 is mounted, directing through the stencil frame 4 (Figure 2) the luminous flux 5, imitating the marking of the" Zebra "type on the surface of the pedestrian crossing 6. Windows 7 simulate enabling or disabling traffic signals. A motion sensor 8 with a control unit connected to a power source, a searchlight 3 is mounted on support 1".

The novelty of the proposed method is the implementation of the illumination of the pedestrian crossing visible, regardless of the time of day, while additional notification of drivers is carried out using a window that simulates a traffic light signal facing the approaching vehicle, and the color of the light of the pedestrian crossing and traffic light window when a pedestrian appears at the pedestrian crossing change from permissive to prohibiting [9].

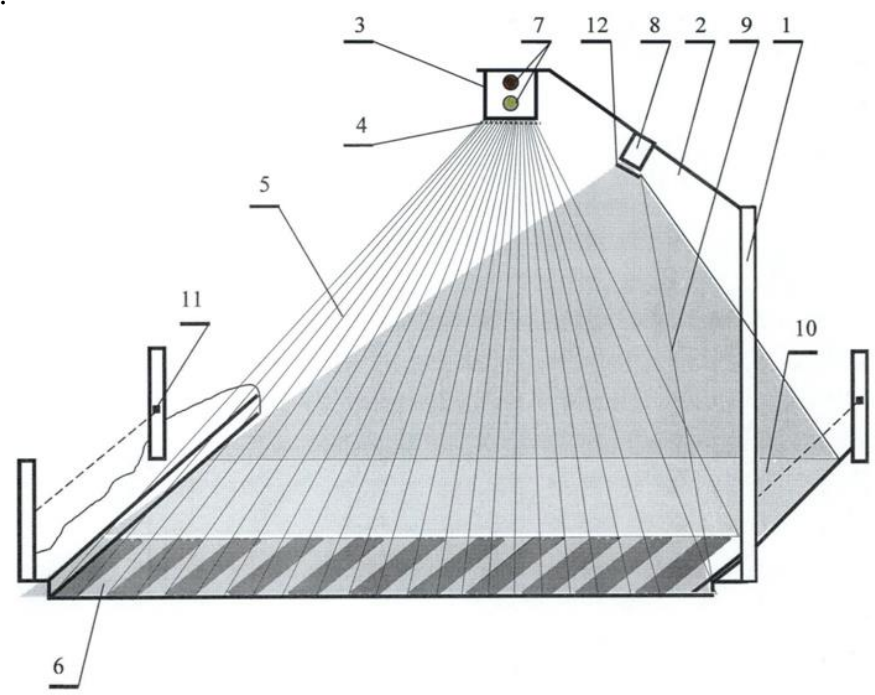

Fig. 1. Device for alerting drivers about presence of a pedestrian at a pedestrian crossing 


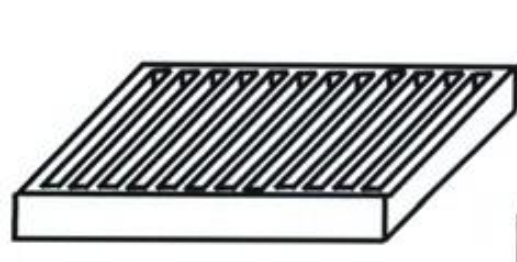

a)

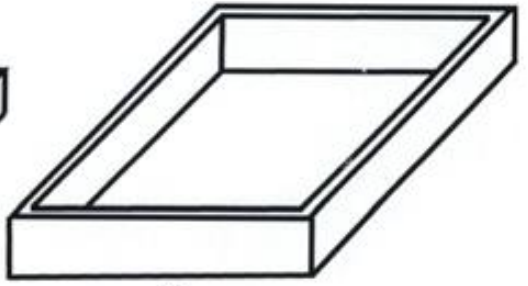

b)

Fig. 2. Guide frame-stencil

a) installed in front of the luminous flux of the LED floodlight,

b) installed in front of the motion sensor

2) Pedestrian crossing.

The work of the invention is as follows [10]: "on the supports of road signs, video cameras 10 (Figure 3) are installed, combined with a device for measuring the speed of a vehicle, directed towards oncoming traffic. Video cameras monitor the presence of vehicles on the road, and a device for measuring vehicle speed records their speed at a distance of 100 and 50 meters from the nearest edge of the pedestrian crossing. At these distances, additional marking lines are applied and additional information signs 3, 5 are installed. When violations of the Traffic Rules are recorded by vehicle drivers, a device 7 is triggered to forcibly stop the vehicle, located 5 meters from the nearest edge of the pedestrian crossing. At the moment of operation of the proposed device, the headlights are reflected from the reflective coating of the surface of the suddenly appeared obstacle, attracting the attention of the driver" [10].

The pedestrian crossing on both sides has platforms 12 (Figure 3) with built-in weight sensors, one of which is a weight sensor 16 on one side and a weight sensor 20 on the opposite side are located on the sidewalk 13, and others are a weight sensor 18 on one side and a sensor weight 19 from the opposite side on the carriageway 1 [10].

To ensure the movement of pedestrians along the pedestrian crossing 14 on the sidewalk 13, a fence 15 is provided on each side. Signals from weight sensors 16, 20 and 18, 19 and video cameras 10 enter control unit 17 (Figures 4, 5).

The device for forced stopping of the vehicle 7 (Figure 3) consists of electromagnets 21 (Figure 6), a shaft 22 with removable rings treated with a reflective compound 23, guides 24 fixed on the frame 27 under the action of springs 25 , an electric motor 26 fixed on the frame 27 and a rotating pulley 28 , on which the cable 29 is wound, fixed at the other end to the shaft $22[12]$. 


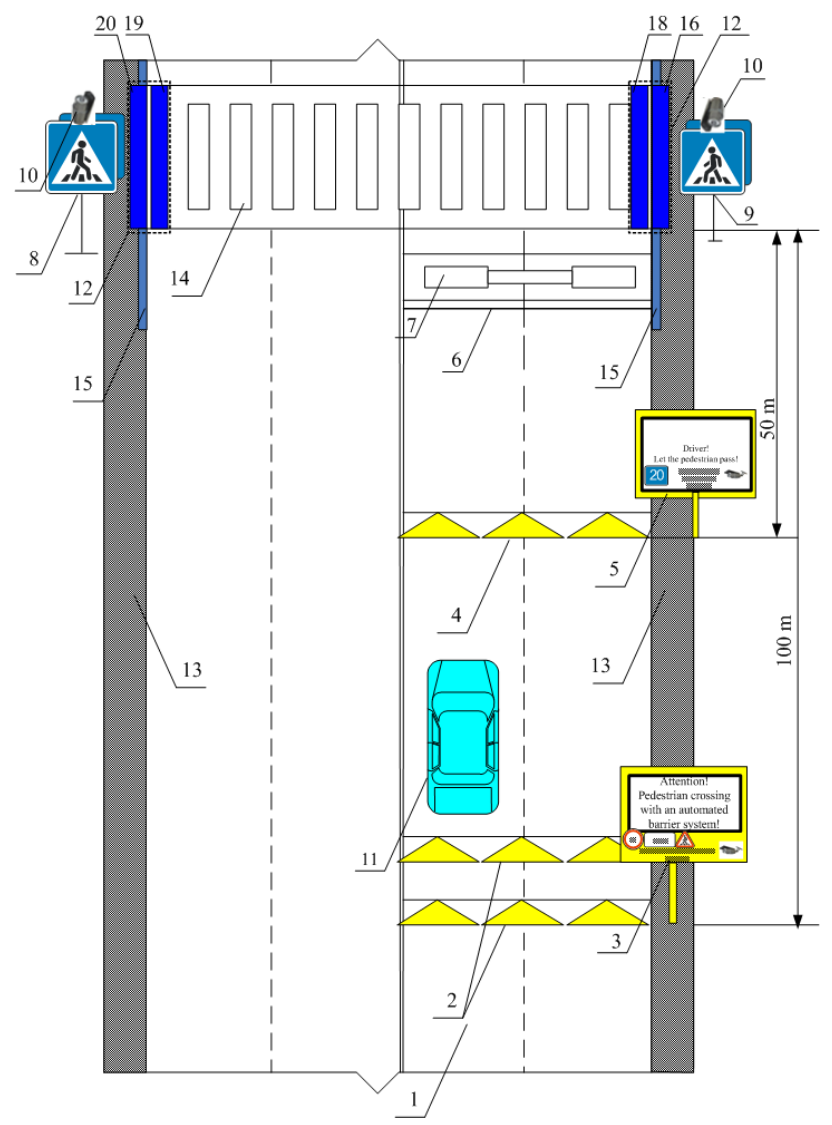

Fig. 3. Pedestrian crossing (prototype of the invention)
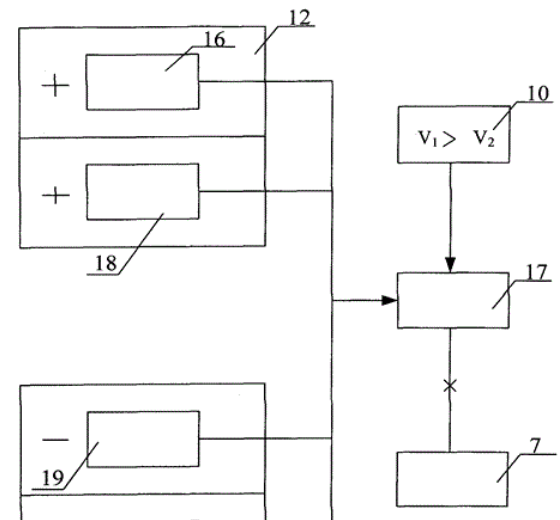

Fig. 4. Fixation by the vehicle deceleration system 


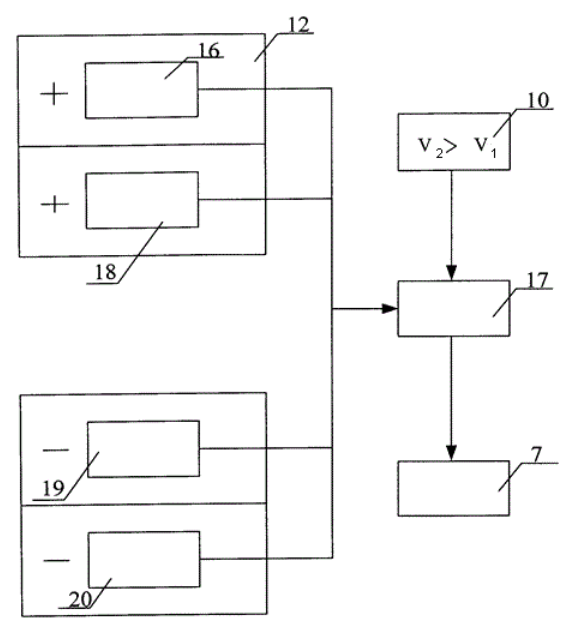

Fig.5. Fixation by the system of absence of deceleration of the vehicle and giving a signal to act on the device for forced stop
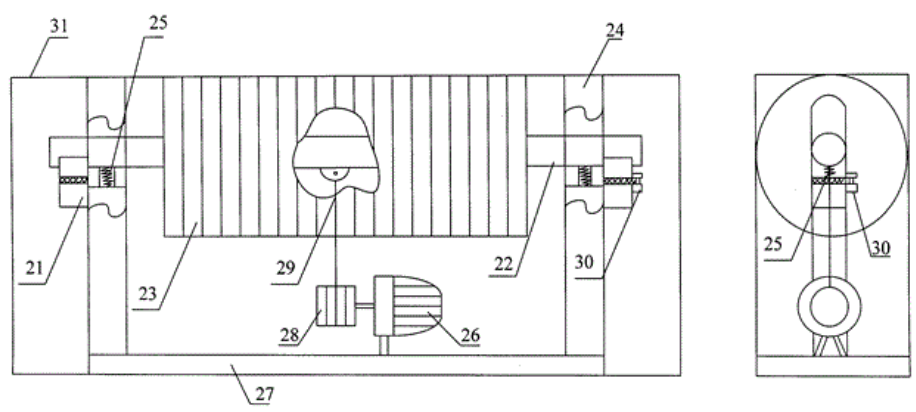

Fig. 6. Device for forced stopping of a vehicle

At the moment of activation of the device for forced stopping of the vehicle, the headlights are reflected from the reflective surface of the surface of the suddenly appeared obstacle, attracting the attention of the driver, who will be forced to stop in front of the obstacle, allowing pedestrians to finish crossing the road [10].

\section{Results}

For the prototype we choose the patent for the invention [10], as the closest to the proposed invention.

The main differences from the invention [10] include:

increasing the number of cameras from $2 \mathrm{x}$ to $4 \mathrm{x}$;

complication of the functionality of the control unit;

modification of the device for forced stopping of a motor vehicle.

The main unit of the device is a control unit that analyzes all information coming from 4 video cameras equipped with devices for determining the speed of vehicles. Cameras are located:

2 on the stands of road signs "Pedestrian crossing" and directed in different directions, each in the direction of the opposite direction of vehicles approaching an unregulated pedestrian crossing;

2 others at a distance of $50 \mathrm{~m}$ in different directions from an unregulated pedestrian crossing. They are installed on road signs 5 (Figure 3). 
The first two cameras send information about the speed of the approaching vehicle v2 to the control unit, recognizes its state registration plate, if the speed $\mathrm{v} 2 \geq 40 \mathrm{~km} / \mathrm{h}$, saves information about violation of the speed limit of traffic rules: date, time, state registration plate, several photographs of the vehicle.

If there was a pedestrian at the pedestrian crossing at that moment, this traffic violation is also indicated. Thus, the driver who drove this vehicle will receive two protocols of traffic violations. In addition, the control unit will wait for a signal for a certain time from the load cell units 16, 18 or 19, 20 (Figure 1.13). The absence of this signal will mean a run over a pedestrian, so the control unit equipped with a transmitting antenna will send a signal about an incident with the coordinates of an unregulated pedestrian crossing to the nearest traffic police department. Upon arrival, the crew must decide on the need to call an ambulance, as well as take measures to search for and arrest the offender.

Video cameras installed at a distance of $50 \mathrm{~m}$ from an unregulated pedestrian crossing send to the control unit information about the speed $\mathrm{v} 1$ of a vehicle approaching the crossing, its category (M1, M3, N3 or, for example, N3O3), the condition of the road surface (dry, wet, covered snow), state registration plate.

If a signal is received from load cells 16,18 or 19, 20 (Figure 3), i.e. a pedestrian is moving along the crossing, and video cameras 10 (Figure 7) recorded an approaching vehicle, then the control unit calculates whether it is a safe speed for a pedestrian using the known formulas [11].

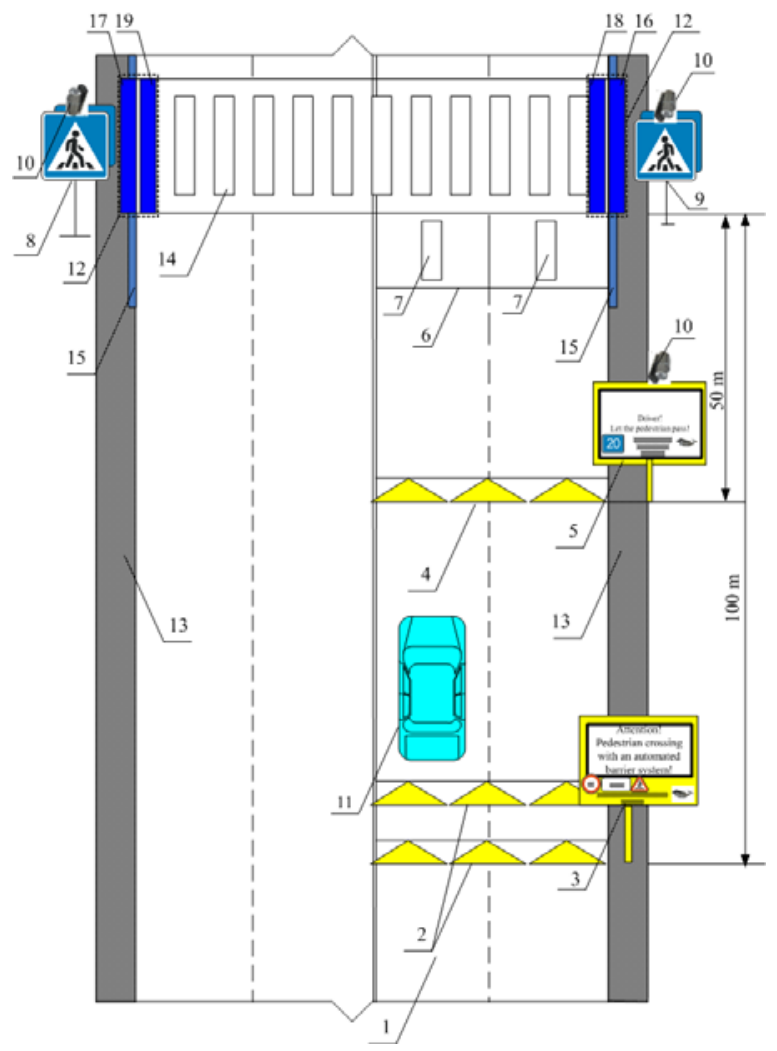

Fig. 7. Equipment of an unregulated pedestrian crossing

If the speed of the vehicle does not correspond to the safe one, as well as if v1 $\geq v 2$, then the control unit will give a signal to turn on the compressor. With the help of the compressor, air will be pumped into the rubber cylinder 7 (Figure 7), equipped with a safety valve to 
relieve excess air pressure and release air from the cylinder after the compressor is turned off.

The technical result of the proposed device is that the driver of the vehicle, approaching the pedestrian crossing $100 \mathrm{~m}$ before it, is warned by road sign 3 (Figure 7). A law-abiding driver reduces the vehicle speed to $40 \mathrm{~km} / \mathrm{h}$. After $50 \mathrm{~m}$, the driver is warned by road sign 5 (Figure 7). A law-abiding driver will reduce the vehicle speed to $20 \mathrm{~km} / \mathrm{h}$. If there is a pedestrian, he stops in front of the pedestrian crossing and lets the pedestrian pass. In the absence of a pedestrian, the driver goes through this crossing without stopping.

If the driver does not reduce the speed of movement in accordance with signs 3 and 5 or increases it, then a lateral convex obstacle appears in front of him, which will force him to resort to emergency braking up to a stop. This psychological effect will be enhanced by the presence of a reflective layer applied to the rubber balloon.

\section{Conclusions}

The presented method for increasing the safety of pedestrian traffic on an unregulated pedestrian crossing is relevant, because road accidents in the Rostov region remain at a high level. Among the total number of accidents, one of the "first" leading places is a collision with a pedestrian. Therefore, any work in the field of improving road safety at pedestrian crossings is relevant [12-14].

The analysis of the work and the patent search for devices that increase the safety of a pedestrian when moving along a pedestrian crossing showed that there is a need to expand the range of such devices.

As a result of the study, a description of a new device for compulsory reduction of the speed of movement is presented. The choice of a prototype device to improve road safety at unregulated pedestrian crossings was justified. A general description of the device and its principle of operation are given. The technical result of the proposed invention is formulated.

\section{References}

1. E.V. Marchenko, Ju.V. Marchenko, S.I. Popov, S.G. Kuren, I.V. Marchenko, Automated transport and storage systems for road transport companies, International Scientific Conference «Construction and Architecture: Theory and Practice for the Innovation Development» (CATPID-2020): IOP Conference Series: Materials Science and Engineering 1083, 012063 (2021) doi: 10.1088/1757-899X/1083/1/012063

2. V.V. Ivanov, S.I. Popov, N.S. Dontsov, Ju.V. Marchenko, N.V. Ryzhkin, Ju.A. Oleynikova, Chemical and mechanical bases of coating application in vibration technological systems, XVI International scientific-technical conference «Dynamics of technical systems» (DTS-2020): IOP Conference Series: Materials Science and Engineering 1029, 012052 (2021) doi:10.1088/1757-899X/1029/1/012052

3. V.V. Ivanov, S.I. Popov, N.S. Dontsov, N.V. Ryzhkin, Ju.A. Oleynikova, Ju.N. Denisenko, Combined process of vibratory processing and oxidation with the use of polymeric environments, VIII International Scientific and Practical Conference «Innovative Technologies in Science and Education» (ITSE-2020): E3S Web of Conferences 210, 01006 (2020) doi.org/10.1051/e3sconf/202021001006

4. A.F. Apalkov, S.A. Apalkov, S.G. Kuren, S.I. Popov, Ju.V. Marchenko, Development of a furrow irrigation method, VIII International Scientific and Practical Conference «Innovative Technologies in Science and Education»(ITSE-2020): E3S Web of Conferences 210, 04009 (2020) doi.org/10.1051/e3sconf/202021004009 
5. S.G. Kuren, G.A. Galchenko, S.I. Popov, Ju.V. Marchenko, N.S. Dontsov, D.S. Drozdov Optimization of transport routes based on environmental indicators, VIII International Scientific and Practical Conference «Innovative Technologies in Science and Education» (ITSE-2020): E3S Web of Conferences 210, 09005, 2020. doi.org/10.1051/e3sconf/202021009005

6. S.V. Teplyakova, A.A. Kotesova, S.I. Popov, A.A. Kotesov, The transition from the sample data to the total aggregate of the final volume and the analysis of this transition laws, International Scientific Conference «Construction and Architecture: Theory and Practice for the Innovation Development» (CATPID-2020): IOP Conference Series: Materials Science and Engineering 913, 042054 (2020) doi:10.1088/1757899X/913/4/042054

7. V.V. Ivanov, S.I. Popov, N.S. Dontsov, A.A. Kotesova, The oxide film formation under vibration processing in the high-resource parts manufacture in transport engineering, International Scientific Conference «Construction and Architecture: Theory and Practice for the Innovation Development» (CATPID-2020): IOP Conference Series: Materials Science and Engineering 913, 042056 (2020) doi:10.1088/1757-899X/913/4/042056

8. A.A. Korotky, E.V. Marchenko, S.I. Popov, Ju.V. Marchenko, N.S. Dontsov, Theoretical foundations of modeling the process of transport vehicles steel ropes structural defects formation, XIII International Scientific and Practical Conference «State and Prospects for the Development of Agribusiness - INTERAGROMASH 2020»: E3S Web of Conferences 175, 05018 (2020) doi.org/10.1051/e3sconf/202017505018

9. V.V. Ivanov, S.I. Popov, N.S. Dontsov, G.E. Ekinil, Ju.A. Oleynikova, Ju.N. Denisenko, Mechanical coating formed under conditions of vibration exposure, XIII International Scientific and Practical Conference «State and Prospects for the Development of Agribusiness - INTERAGROMASH 2020»: E3S Web of Conferences 175, 05023 (2020) doi.org/10.1051/e3sconf/202017505023

10. B.Y. Kalmykov, Mechatronic intelligent bus control system, IEEE East-West Design \& Test Symposium (EWDTS 2017) Proceedings, 8110089 (2017)

11. N.N. Yazvinskaya, N.E. Galushkin, D.N. Galushkin, B.Y. Kalmykov, Analysis and comparison of generalized Peukert's equations parameters for nickel-cadmium batteries with pocket and sintered electrodes, International Journal of Electrochemical Science 15(1), 412-423 (2020)

12. A.N. Drovnikov, B.Yu. Kalmykov, On the development trends of the machine-tractor park of the agro-industrial complex of Russia, IOP Conference Series: Materials Science and Engineering. 2019 International Conference on Innovations in Automotive and Aerospace Engineering, ICI2AE 2019, 012078 (2019)

13. A.N. Drovnikov, B.Yu. Kalmykov, Technological bases of the improvement of agricultural transport-technological machines, IOP Conference Series: Materials Science and Engineering. 2019 International Conference on Innovations in Automotive and Aerospace Engineering, ICI2AE 2019, 012084 (2019)

14. B.Y. Kalmykov, S.G. Stradanchenko, A.Y. Sirotkin, A.S. Garmider, Y.B. Kalmykova, Effect of the bus bodywork on impact strength properties in roll-over, ARPN Journal of Engineering and Applied Sciences 11(17), 10205-10208 (2016)

15. B.Y. Kalmikov, N.A. Ovchnnikov, O.M. Kalmikova, I.K. Guguyev, I.V. Kushnariva, Application of the method of distribution of the total energy of impact on the bearing elements of the body of the bus when calculating the failure loads, ARPN Journal of Engineering and Applied Sciences 10(10), 4366-4371 (2015) 
16. I.Y. Visotski, N.A. Ovchinnikov, I.M. Petriashvili, Y.B. Kalmikova, B.Yu. Kalmykov, The use of additional devices for reducing the deformation of the bus body when tipping,ARPN Journal of Engineering and Applied Sciences 10(12), 5150-5156 (2015) 